\title{
Internship commencement during COVID-19: the impact of an extended induction model
}

\author{
Alexandra Foley ${ }^{1} \cdot$ Feargal Donaghy $^{1} \cdot$ Gerard A. Sheridan $^{1,2}\left(\right.$ Clarán Stanley $^{1,2} \cdot$ Ann-Maria Byrne $^{1,2}$. \\ Arnold D. K. Hill ${ }^{1,2} \cdot$ Hannan Mullett ${ }^{1,2}$
}

Received: 19 January 2021 / Accepted: 2 February 2021 / Published online: 8 February 2021

(c) Royal Academy of Medicine in Ireland 2021

\begin{abstract}
Background The COVID-19 pandemic necessitated an enforced 8-week induction period (18 May to 12 July 2020) for all new interns in Ireland. These unprecedented circumstances presented a unique opportunity to assess this induction period. Aim To assess the impact of a prolonged induction period on the technical abilities of interns embarking on their clinical careers.

Method We distributed a 12-item questionnaire to new interns at our institution during the COVID-19 pandemic. Section 1 of the questionnaire was designed to assess the rate of self-reported improvement in the successful and independent execution of practical 'intern' tasks. Section 2 of the questionnaire captured the subjective experience of interns during this time in relation to the effectiveness of an 8-week induction period with senior intern support available. Statistical analysis of categorical predictor and ordinal outcome variables was performed using the two-sample Wilcoxon rank-sum (Mann-Whitney) test.

Results Our results demonstrated a statistically significant improvement in the proficiency at first attempt phlebotomy in week 8 compared with week $1(p<0.0001)$. There was a significant improvement in placing first-attempt peripheral IV lines in week 8 compared with week $1(p<0.001)$. Regarding the need for senior assistance, we demonstrated a statistically significant reduction in week 8 compared with week $1(p=0.046)$. There were $95.56 \%(n=43)$ of interns that said they would recommend the induction period for future incoming interns.

Conclusion The COVID-19 pandemic has inadvertently identified a model of internship induction that benefits interns, their colleagues and their patients through the production of more technically capable interns.
\end{abstract}

Keywords Clinical skills $\cdot$ COVID-19 $\cdot$ Induction $\cdot$ Intern $\cdot$ Technical skills $\cdot$ Training

\section{Background}

\section{Highlights}

- We demonstrated a statistically significant improvement in the proficiency at first-attempt peripheral phlebotomy in week 8 compared with week $1(p<0.0001)$

- We demonstrated a statistically significant improvement in the proficiency at placing first-attempt peripheral IV lines in week 8 compared with week $1(p<0.001)$

- We demonstrated a statistically significant reduction in the need for interns to request senior help in week 8 compared with week $1(p=0.046)$

- There were $95.56 \%(n=43)$ of interns that said they would recommend the induction period for future incoming interns.

- Over $90 \%$ believed that an induction period of 2-4 weeks was sufficient to prepare an intern to commence in their new post.

Gerard A. Sheridan

sheridga@tcd.ie

Extended author information available on the last page of the article
The transition of newly qualified doctors from university to internship has long been a source of significant stress $[1,2]$. In an attempt to mitigate this issue in Ireland, a structured 1-week intern induction was introduced in 2019 [3]. Just 1 year later in 2020, newly appointed interns found themselves commencing their professional careers in the midst of a global health crisis unparalleled in its global impact by any disease in recent history. The COVID-19 pandemic necessitated an enforced 8-week induction period (18 May 2020 up to 12 July 2020) for all new interns in Ireland to facilitate an increased workload, reconfigured bed capacity and reduced staffing numbers as a result of sick leave and self-isolation [4]. This series of events has provided the intern class of 2020 with 8 weeks of a structured internship induction compared 
Table 1 Section 1: Intern technical tasks

\begin{tabular}{|c|c|c|c|c|c|}
\hline Questions & A & B & $\mathrm{C}$ & $\mathrm{D}$ & $\mathrm{E}$ \\
\hline (1) On average, what was your success rate with first time phlebotomy in week 1 ? & $0-20 \%$ & $20-40 \%$ & $40-60 \%$ & $60-80 \%$ & $80-100 \%$ \\
\hline (2) On average, what was your success rate with first time phlebotomy in week 8 ? & $0-20 \%$ & $20-40 \%$ & $40-60 \%$ & $60-80 \%$ & $80-100 \%$ \\
\hline (3) On average, what was your success rate with first time IV line insertion in week 1 ? & $0-20 \%$ & $20-40 \%$ & $40-60 \%$ & $60-80 \%$ & $80-100 \%$ \\
\hline (4) On average, what was your success rate with first time IV line insertion in week 8 ? & $0-20 \%$ & $20-40 \%$ & $40-60 \%$ & $60-80 \%$ & $80-100 \%$ \\
\hline $\begin{array}{l}\text { (5) How often did you need a senior colleague to assist with tasks after you had attempted } \\
\text { in week } 1 \text { ? }\end{array}$ & Never & Rarely & Sometimes & Often & Always \\
\hline $\begin{array}{l}\text { (6) How often did you need a senior colleague to assist with tasks after you had attempted } \\
\text { in week } 8 \text { ? }\end{array}$ & Never & Rarely & Sometimes & Often & Always \\
\hline
\end{tabular}

with the previously standard 1 week of induction. These unprecedented circumstances presented a unique opportunity to assess the impact of a prolonged induction period on the clinical acumen and technical abilities of new interns embarking on their clinical careers.

\section{Aim}

To assess the impact of a prolonged induction period on the technical abilities of interns embarking on their clinical careers.

\section{Methods}

\section{Study design}

We created and distributed a 12-item electronic, anonymous and voluntary questionnaire to new interns commencing their positions at our institution during the COVID-19 pandemic. The aim of the questionnaire was three-fold. Section 1 of the questionnaire was designed to assess the rate of self-reported improvement in the successful and independent execution of practical 'intern' tasks (i.e. peripheral line insertion (first attempt) and phlebotomy (first attempt) and reliance on senior colleagues) at two timepoints (Table 1):

1. 18 May 2020 (week 1) (expedited internship commencement date due to COVID-19)

2. 13 July 2020 (week 8) (8 weeks later at the originally intended internship commencement date)

Section 2 of the questionnaire was designed to capture the subjective experience of interns during this time in relation to the effectiveness of an 8-week induction period with senior intern support available (Table 2). The questionnaire was circulated via an electronic messaging platform on 6 August 2020. The answers provided by each participant registered remained anonymous.

Our survey also included a third section consisting of two open-ended questions with free text answers allowing us to capture the subjective experiences of the intern class of the 2020 pandemic.

Table 2 Section 2: Perception of an 8-week induction period

\begin{tabular}{|c|c|c|c|c|c|}
\hline Questions & A & $\mathrm{B}$ & $\mathrm{C}$ & $\mathrm{D}$ & $\mathrm{E}$ \\
\hline $\begin{array}{l}\text { (7) How long did it take for you to feel 'comfortable' in } \\
\text { your job as an intern? }\end{array}$ & 1-3 days & 4-6 days & 7-14 days & 2-4 weeks & $>4$ weeks \\
\hline $\begin{array}{l}\text { (8) How helpful was the extended induction period for } \\
\text { you? }\end{array}$ & Extremely helpful & Very helpful & Somewhat helpful & Not so helpful & No help at all \\
\hline $\begin{array}{l}\text { (9) Would you recommend an extended induction for } \\
\text { interns in future years? }\end{array}$ & Yes & No & Indifferent & & \\
\hline (10) How much of an induction would you recommend? & 2 weeks & 4 weeks & 6 weeks & 8 weeks & \\
\hline $\begin{array}{l}\text { (11) Do you think the induction prepared you better for the } \\
\text { changeover? }\end{array}$ & Yes & No & Indifferent & & \\
\hline $\begin{array}{l}\text { (12) Do you think that working as an intern during } \\
\text { COVID-19 has made you more resilient? }\end{array}$ & Yes & No & & & \\
\hline
\end{tabular}




\section{Statistical analysis}

Simple descriptive statistics were used to describe the distribution of answers for each questionnaire item. Results were illustrated in bar chart format. The questionnaire answer options were all ordinal variables in nature. Statistical analysis of categorical predictor and ordinal outcome variables was performed using the two-sample Wilcoxon rank-sum (Mann-Whitney) test. A $p<0.05$ was taken to be statistically significant. The statistical software used was Stata/IC 13.1 for Mac (64-bit Intel).

\section{Results}

We received 45 completed surveys from a total of 57 interns that were contacted giving a total response rate of $78.95 \%$.

\section{Section 1: Intern technical tasks}

\section{Phlebotomy}

In week 1 , at the beginning of the extended induction date on 18 May 2020, 6.67\% $(n=3)$ were successful $0-20 \%$ of the time, $17.78 \%(n=8)$ were successful $20-40 \%$ of the time, $42.22 \%$ $(n=19)$ were successful $40-60 \%$ of the time, $24.44 \%(n=11)$ were successful $60-80 \%$ of the time and $8.89 \%(n=4)$ were successful $80-100 \%$ of the time. Eight weeks later, at the original internship commencement date, $0 \%(n=0)$ were successful $0-20 \%$ of the time, $0 \%(n=0)$ were successful $20-40 \%$ of the time, $8.89 \%(n=4)$ were successful $40-60 \%$ of the time, $33.33 \%(n=15)$ were successful $60-80 \%$ of the time and $57.78 \%(n=26)$ were successful $80-100 \%$ of the time. These results demonstrated a statistically significant improvement in the proficiency at first attempt peripheral phlebotomy in week 8 compared with week $1(p<0.0001)$ (Fig. 1).
Fig. 1 First-attempt phlebotomy success rates at week 1 and week 8

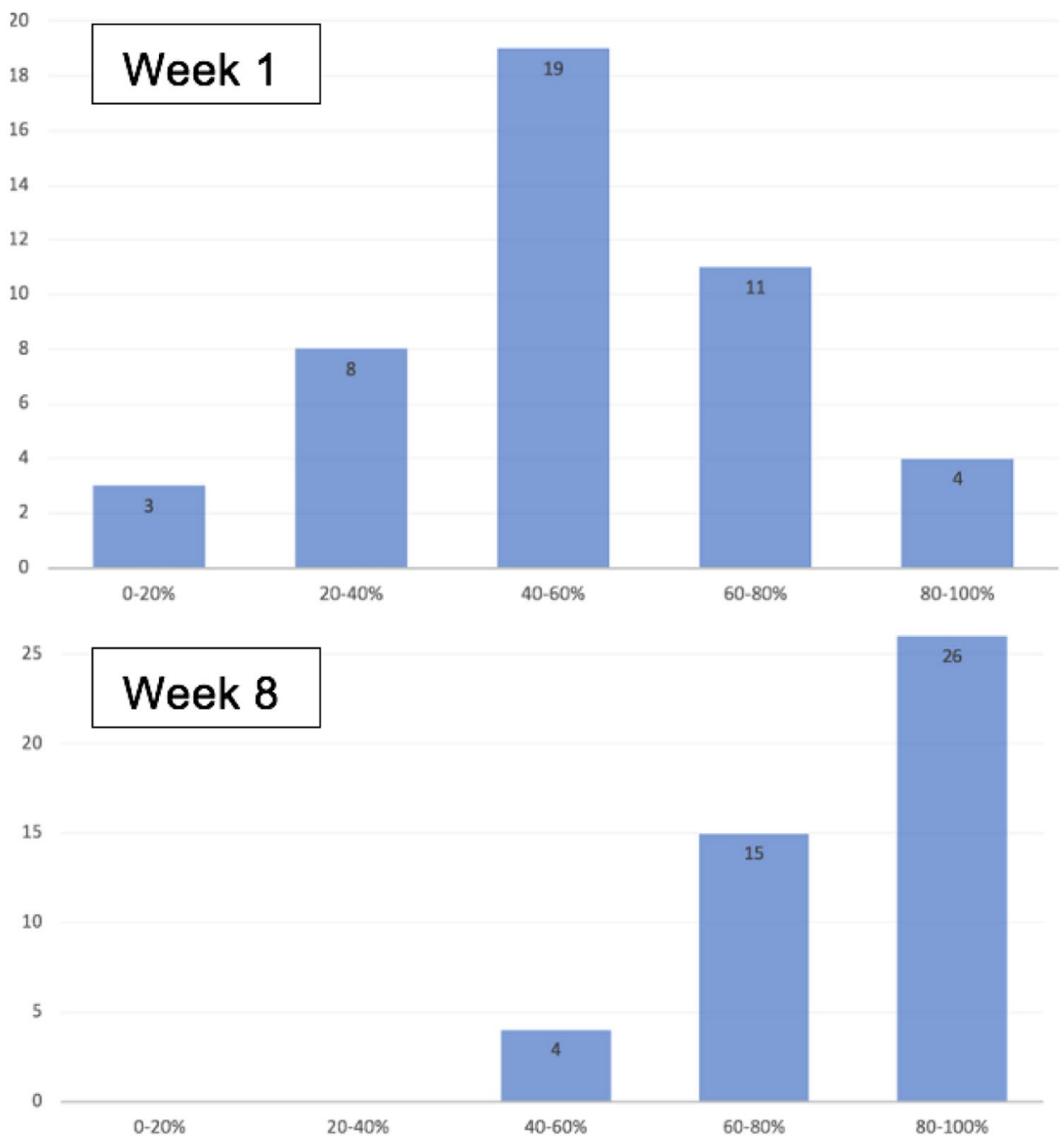




\section{Peripheral IV line insertion}

With regard to proficiency at inserting peripheral intravenous lines at week 1: $24.44 \%(n=11)$ were successful $0-20 \%$ of the time, $31.11 \%(n=14)$ were successful $20-40 \%$ of the time, $22.22 \%(n=10)$ were successful $40-60 \%$ of the time, $15.56 \%(n=7)$ were successful $60-80 \%$ of the time and $6.67 \%$ $(n=3)$ were successful $80-100 \%$ of the time. At week 8, 0\% $(n=0)$ were successful $0-20 \%$ of the time, $2.22 \%(n=1)$ were successful $20-40 \%$ of the time, $24.44 \%(n=11)$ were successful $40-60 \%$ of the time, $31.11 \%(n=14)$ were successful $60-80 \%$ of the time and $42.22 \%(n=19)$ were successful $80-100 \%$ of the time. These results demonstrated a statistically significant improvement in the proficiency at placing first-attempt peripheral IV lines in week 8 compared with week $1(p<0.001)$ (Fig. 2).

\section{Senior assistance}

In relation to the need to seek help from a senior colleague for an intern task at week 1: $8.89 \%(n=4)$ always needed help, 42.22\% ( $n=19$ ) often needed help, $44.44 \%(n=20)$ sometimes needed help and $4.44 \%(n=2)$ rarely needed help. At week 8, 0\% $(n=0)$ always needed help, 2.22\% $(n=1)$ often needed help, $35.56 \%(n=16)$ sometimes needed help and $62.22 \%(n=28)$ rarely needed help. These results demonstrated a statistically significant reduction in the need for interns to request senior help in week 8 compared with week $1(p=0.046)$ (Fig. 3).

\section{Section 2: Perception of an 8-week induction period}

When asked how long it took to feel comfortable in their job as an intern, $13.33 \%(n=6)$ needed $7-14$ days, $26.67 \%$ $(n=12)$ needed 2- 4 weeks and $53.3 \%(n=24)$ needed more than 4 weeks (Fig. 4). A total of $93.3 \%(n=42)$ of interns found the 8 -week induction period to be either very helpful or extremely helpful. There were $95.56 \%(n=43)$ of interns that said they would recommend the induction period for future incoming interns. Over $90 \%$ believed that an induction period of 2-4 weeks was sufficient to prepare
Fig. 2 First-attempt peripheral line insertion success rates at week 1 and week 8

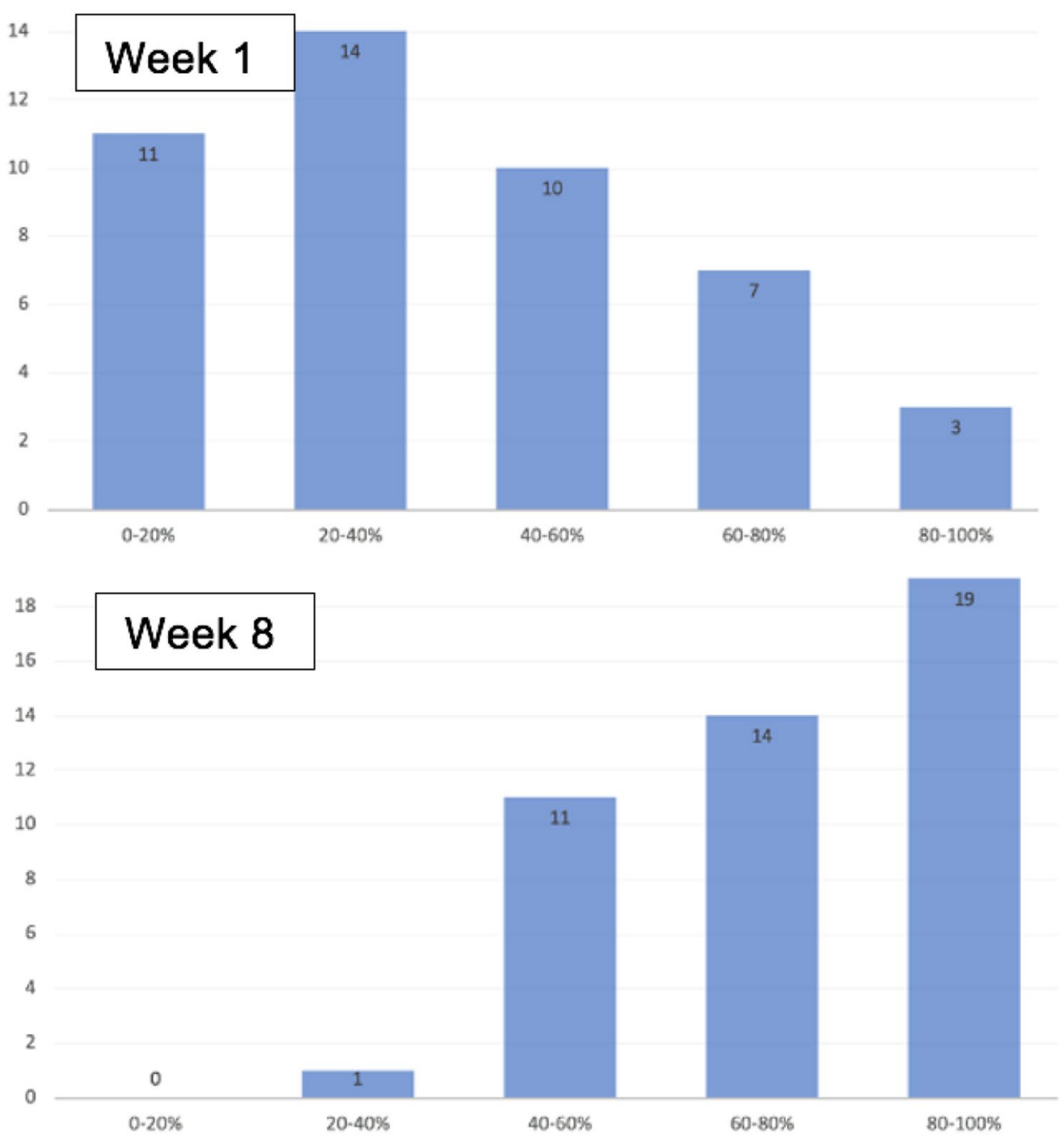


Fig. 3 Request for senior help at week 1 and week 8

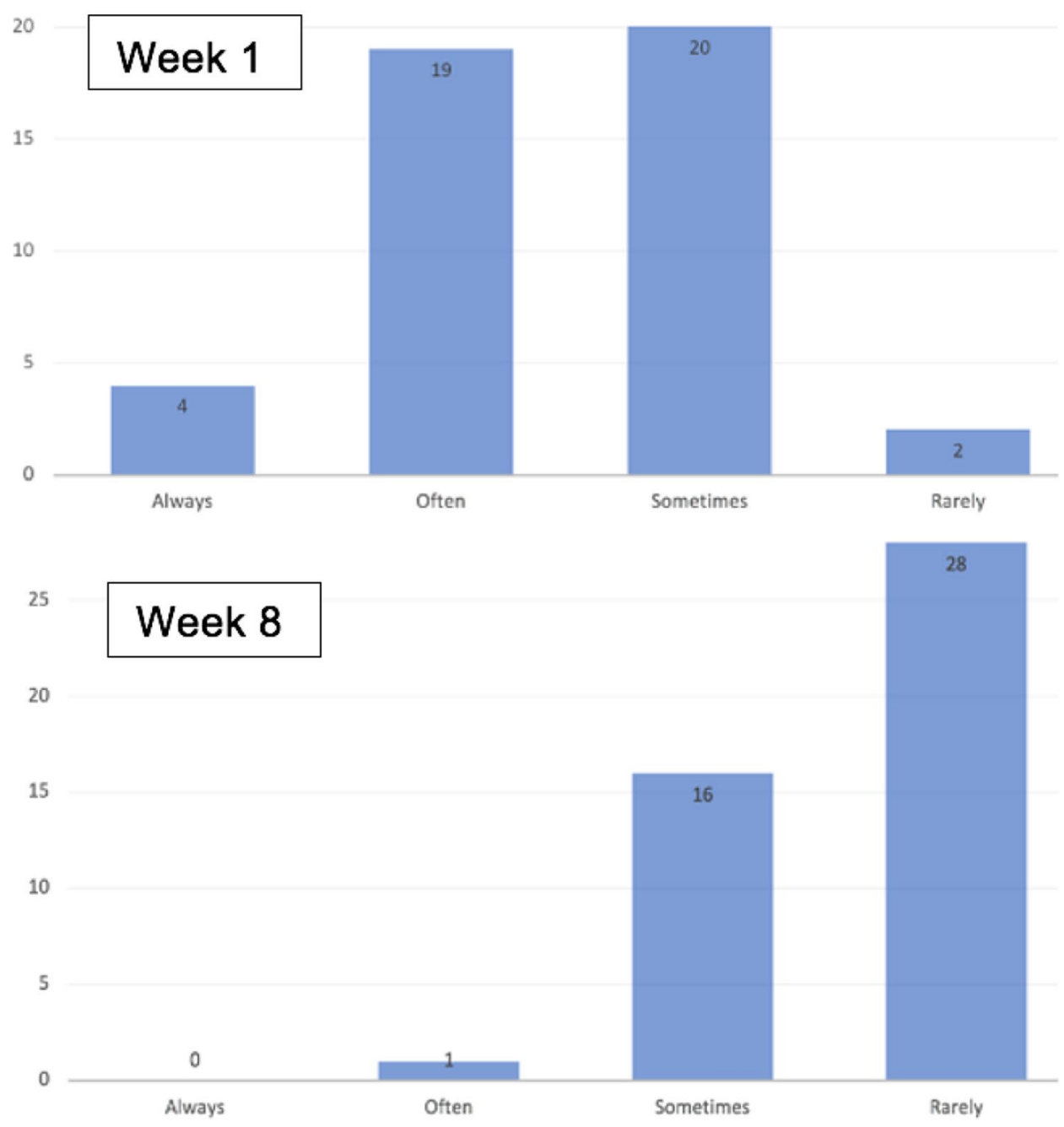

an intern to commence in their new post. When asked if they thought the induction period helped to prepare for the original commencement date (week 8$), 95.56 \%(n=43)$ agreed. With regard to whether working during COVID-19 has made them more resilient for future positions, 59.09\% $(n=26)$ said yes and $40.91 \%(n=18)$ said no. During the 8 -week induction period, of the 45 completed questionnaires, $13.33 \%(n=6)$ had to self-isolate due to being a COVID-19
Fig. 4 How long did it take for you to feel 'comfortable' in your job as an intern?
25

\begin{tabular}{|l|l}
24 & 24
\end{tabular}

20

15

10

5

0

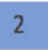

4-6 days

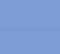


Table 3 Thematic representation of the negative aspects of COVID-19

\begin{tabular}{ll}
\hline Responses & Percent $(n)$ \\
\hline Longer intern year without graduation or postgraduation vacation & $24.24(8)$ \\
The practicalities of PPE/masks/scrubs & $18.18(6)$ \\
Social distancing from loved ones & $12.12(4)$ \\
Sudden on-call responsibilities with limited exposure to basic intern tasks & $12.12(4)$ \\
Frustration while waiting to qualify while 'senior interns' worked during the peak of pan- & $12.12(4)$ \\
demic & \\
Difficult to establish role as 'junior intern' within established team dynamics & $9.09(3)$ \\
Fear of getting COVID-19 and passing it on to team/loved ones & $9.09(3)$ \\
Missing teaching/examination opportunities due to cancellation & $3.03(1)$ \\
\hline
\end{tabular}

close contact and $2.22 \%(n=1)$ had to self-isolate due to testing positive for COVID-19.

\section{Section 3: Perception of internship during COVID-19}

Our survey also included two open questions allowing us to capture the subjective experiences of the intern class of the 2020 pandemic. We asked the respondents to describe the most difficult and the most rewarding aspects of commencing internship during the COVID-19 pandemic. Of the 45 participants who completed the survey, $73.33 \%$ $(n=33)$ answered these open questions. Thematic analysis is summarised in Tables 3 and 4.

\section{Discussion}

It is generally accepted that interns feel unprepared when commencing their positions in both Ireland and the UK [5, 6]. However, recent changes in medical education appear to have improved this sense of preparedness for the workplace [7]. These changes include an increased focus on intern shadowing, the teaching of practical skills and clinical simulation. Despite these clinical reforms, most interns still find the transition stressful due to newly gained responsibility, the need to manage uncertainty, working in multidisciplinary teams, experiencing the sudden death of patients and feeling unsupported [8]. It seems intuitive

Table 4 Thematic Representation of the Positive Aspects of COVID-19

\begin{tabular}{lc}
\hline Responses & Percent $(n)$ \\
\hline Extended supervised induction period & $41.18(14)$ \\
Support from senior interns & $26.47(9)$ \\
Contributing to the fight against COVID-19 & $11.76(4)$ \\
Increased resilience/self-discipline & $5.88(2)$ \\
Becoming more aware of contact precautions & $2.94(1)$ \\
Wearing scrubs everyday & $2.94(1)$ \\
The first payslip & $2.94(1)$ \\
Skipping the queue at the grocery store & $2.94(1)$ \\
\hline
\end{tabular}

that exposing interns to the practical requirements of the position through a standardised and mandatory induction would alleviate most of these stressors.

Despite a general consensus in favour of induction and its intuitive merits, there is a paucity of evidence surrounding its efficacy particularly in Ireland [9]. The expedited commencement date for interns during the COVID-19 pandemic ushered in an 8-week overlap between exiting and entering interns. This 8 -week period of supervised induction provided us with the opportunity to assess the impact of such a period on the technical proficiency in the performance of the daily tasks performed by interns in a clinical setting. Our findings support the claim that significantly higher rates of technical success can be achieved with an 8-week induction model for phlebotomy and peripheral IV line insertion with significantly less reliance on senior colleague support. This desirable outcome of technical proficiency produces capable, competent and confident interns. Producing an intern group that is adept at their tasks on day 1 of their independent practice on the ward is in the interest of all interns, their team members and their patients. Our findings are supported by evidence suggesting that extended induction improves performance of objectively assessed clinical skills while simultaneously reducing intern anxiety levels $[10,11]$. Among interns, there appears to be an agreement that the shadowing of 'senior interns' is the most valued aspect of this induction period and that 1 -week induction is too short $[12,13]$. Indeed, based on our results of intern opinion, we propose that a period of induction of up to 4 weeks prior to commencing independent internship is likely to be sufficient to arm interns with all the relevant technical skills required to perform their daily tasks. The added benefit of interns being familiar with the current patients at the time of NCHD changeover is highly desirable and is also likely to increase patient safety through continuity of care at the time of changeover.

This study demonstrates the efficacy of an extended induction period in achieving a statistically significant improvement in technical proficiency. It appears that an 8-week induction period is neither feasible nor necessary in the absence of a global pandemic as the majority of interns recommended just a 2-4week induction period. This approach to intern commencement 
would appear to represent a prudent use of healthcare resources which would benefit intern, patient and senior team members alike.

\section{Limitations}

The outcome variables are self-reported and so are subject to some recall bias. The trend across all outcomes was persistent and pervasive indicating that the results reported here are likely to represent a real effect.

\section{Conclusion}

A period of clinical induction of 8 weeks for new interns significantly improves success rates in the performance of technical skills including first-time phlebotomy and first-time peripheral IV line insertion. There is also a significantly lower reliance on senior colleagues after this induction period. The overwhelming majority of interns were in favour of a 4-week induction period being introduced as standard practice for all new interns. The COVID-19 pandemic has inadvertently identified a model of internship induction that benefits interns, their colleagues and their patients through the production of significantly more technically capable interns.

\section{Declarations}

Ethics approval All procedures performed in studies involving human participants were in accordance with the ethical standards of the institutional and/or national research committee and with the 1964 Helsinki declaration and its later amendments or comparable ethical standards. This article does not contain any studies with animals performed by any of the authors.

Informed consent Informed consent was obtained from all individual participants included in the study.

Conflict of interest The authors declare that they have no conflict of interest.

\section{References}

1. Hannan E, Breslin N, Doherty E et al (2018) Burnout and stress amongst interns in Irish hospitals: contributing factors and potential solutions. Ir J Med Sci 187(2):301-307. https:// doi.org/10.1007/s11845-017-1688-7 (Epub 2017 Oct 9 PMID: 28990151)

2. Paice E, Rutter H, Wetherell M et al (2002) Stressful incidents, stress and coping strategies in the pre-registration house officer year. Med Educ 36(1):56-65

3. Rosarii Mannion, National Director, Human Resources (25th June 2019) Memo regarding Payment for Intern Induction July 2019. Available at: https://www.hse.ie/eng/staff/benefitsservices/memofrom-ndhr-re-intern-induction-payment-25jun19.pdf

4. HSE Press Release (10 ${ }^{\text {th }}$ April 2020): Increased number of medical interns to be recruited earlier to support effort against COVID19 Available at: https://www.hse.ie/eng/services/news/media/ pressrel/increased-number-of-medical-interns-to-be-recruitedearlier-to-support-effort-against-covid-19.html

5. Hannon FB (2000) A national medical education needs' assessment of interns and the development of an intern education and training programme. Med Educ 34(4):275-284

6. Miles S, Kellett J, Leinster SJ (2015) Foundation doctors' induction experiences. BMC Med Educ 15:118

7. Lachish S, Goldacre MJ, Lambert T (2016) Self-reported preparedness for clinical work has increased among recent cohorts of UK-trained first-year doctors. Postgrad Med J 92(1090):460-465

8. Brennan N, Corrigan O, Allard J et al (2010) The transition from medical student to junior doctor: today's experiences of Tomorrow's Doctors. Med Educ 44(5):449-458

9. Monrouxe LV, Grundy L, Mann M et al (2017) How prepared are UK medical graduates for practice? A rapid review of the literature 2009-2014. BMJ Open 7(1):e013656

10. Evans DE, Wood DF, Roberts CM (2004) The effect of an extended hospital induction on perceived confidence and assessed clinical skills of newly qualified pre-registration house officers. Med Educ 38(9)

11. Van Hamel C, Jenner LE (2015) Prepared for practice? A national survey of UK foundation doctors and their supervisors. Med Teach 37(2):181-188

12. Berridge EJ, Freeth D, Sharpe J, Roberts CM (2007) Bridging the gap: supporting the transition from medical student to practising doctor-a two-week preparation programme after graduation. Med Teach 29(2-3):119-127

13. Abuhusain H, Chotirmall SH, Hamid N, O'Neill SJ (2009) Prepared for internship? Ir Med J 102(3):82-84

\title{
Authors and Affiliations
}

\author{
Alexandra Foley ${ }^{1} \cdot$ Feargal Donaghy $^{1} \cdot$ Gerard A. Sheridan ${ }^{1,2}$ (D) Ciarán Stanley ${ }^{1,2} \cdot$ Ann-Maria Byrne $^{1,2}$. \\ Arnold D. K. Hill ${ }^{1,2} \cdot$ Hannan Mullett ${ }^{1,2}$ \\ Alexandra Foley \\ Alexandra.foley@ucdconnect.ie \\ Feargal Donaghy \\ feargaldonaghy@rcsi.ie \\ Ciarán Stanley \\ ciaranstanley@rcsi.ie \\ Ann-Maria Byrne \\ Arnold D. K. Hill \\ adkhill@ rcsi.ie \\ Hannan Mullett \\ hannanmullett@icloud.com \\ 1 Beaumont University Hospital, Dublin, Ireland \\ 2 Royal College of Surgeons in Ireland, Dublin, Ireland
}

Ann_maria_byrne@hotmail.com 